\title{
Forward tunneling current in Pt/p-InGaN and Pt/n-InGaN Schottky barriers in a wide temperature range
}

\author{
Engin Arslan ${ }^{\mathrm{a}, *}$, Hüseyin Çakmak ${ }^{\mathrm{a}}$, Ekmel Özbay ${ }^{\mathrm{a}, \mathrm{b}}$ \\ a Nanotechnology Research Center, Department of Physics, Bilkent University, Bilkent, 06800 Ankara, Turkey \\ ${ }^{\mathrm{b}}$ Department of Electrical and Electronics Engineering, Bilkent University, Bilkent, 06800 Ankara, Turkey
}

\section{A R T I C L E I N F O}

\section{Article history:}

Received 4 April 2012

Received in revised form 15 May 2012

Accepted 6 July 2012

Available online 27 July 2012

\section{Keywords:}

InGaN

Tunneling

Schottky

MOCVD

\begin{abstract}
A B S T R A C T
The current-transport mechanisms of the Pt contacts on $p$-InGaN and $n$-InGaN were investigated in a wide temperature range $(80-360 \mathrm{~K})$ and in the forward bias regime. It was found that the ideality factor $(n)$ values and Schottky barrier heights (SBHs), as determined by thermionic emission (TE), were a strong function of temperature and $\Phi_{b 0}$ show the unusual behavior of increasing linearly with an increase in temperature from 80 to $360 \mathrm{~K}$ for both Schottky contacts. The tunneling saturation $\left(J_{T U}(0)\right)$ and tunneling parameters $\left(E_{0}\right)$ were calculated for both Schottky contacts. We observed a weak temperature dependence of the saturation current and a fairly small dependence on the temperature of the tunneling parameters in this temperature range. The results indicate that the dominant mechanism of the charge transport across the Pt $/ p$-InGaN and Pt/n-InGaN Schottky contacts are electron tunneling to deep levels in the vicinity of mixed/screw dislocations in the temperature range of 80-360 K.
\end{abstract}

(c) 2012 Elsevier B.V. All rights reserved.

\section{Introduction}

Because of the wide and direct-energy band gap, the nitride semiconductors, such as GaN, InGaN, AlGaN, AlInN and AlGaInN alloys are very attractive for the fabrication of visible-light-emitting diodes (LEDs) covering the violet, blue, and bluish-green region and are promising for short-wavelength laser diodes (LD) [1-4]. Because of the broad alloy band-gap energies tunability of the In$\mathrm{GaN}$, from near 0.7 up to $3.4 \mathrm{eV}$, it has been widely used as active layers for high-efficiency blue and green light-emitting diodes (LED) and laser diodes [2-4].

It is a challenging task to grow high-quality InGaN that is a few hundred nanometers thick, and has been less successful [5]. There are two main reasons for the limited success. The first is the degradation of the InGaN film quality with thickness due to the lattice mismatch between the underlying GaN, substrate and InGaN layer. There are still no widely available lattice matched GaN substrates for the growth of wurzite GaN. Because of the lattice mismatch between the GaN and substrates, extended defects in c-axis oriented GaN grown on sapphire $\left(\mathrm{Al}_{2} \mathrm{O}_{3}\right)$, silicon carbide $(\mathrm{SiC})$ and silicon substrates including threading dislocations (TDs), stacking faults bounded by Shockley and Frank partial dislocations and inversion domains are commonly observed [6,7]. The other reason limiting

\footnotetext{
* Corresponding author at: Nanotechnology Research Center, Department of Physics, Bilkent University, Bilkent, 06800 Ankara, Turkey. Tel.: +90 031229010 20; fax: +9003122901015.

E-mail address: engina@bilkent.edu.tr (E. Arslan).
}

the structural quality is the tendency of thicker InGaN to phase segregate into In-rich and Ga-rich alloy regions during the deposition process, especially as the indium fraction increases [5]. On the other hand, because of native point defects and a high $n$-type background carrier concentration, the InGaN alloys have an extreme affinity to being the doped $n$-type, which results in a big problem of $p$-type doping InGaN alloys [5,8,9].

It is of great importance to fabricate Schottky contacts that have large Schottky barriers and good thermal stability in the realization of optoelectronic devices. Many experimental and theoretical studies of the current transport mechanism in Schottky barriers have been reported in the literature. In these devices, there is a number of carrier transport mechanisms such as thermionic-emission (TE), thermionic-field-emission (TFE), quantum mechanical tunneling, multi-step tunneling, minority carrier injection and recombination-generation, and usually one of them may dominate over the others within certain temperature and voltage regions [10].

Much research has been reported on the current transport mechanisms on metal Schottky contacts on GaN, AlGaN epilayer, AlInN/GaN and AlGaN/GaN heterostructures. Balyaev et al. [11] and Evstropov et al. [12] showed that the current flow in the III$\mathrm{V}$ heterojunctions is generally governed by multistep tunneling with the involvement of dislocations even at room temperature. They demonstrated that an excess tunnel current can be attributed to dislocations. A model of tunneling through a space charge region (SCR) along a dislocation line (tube) is suggested [11,12]. Dislocations with a screw component and V-defects have been suggested for the primary tunneling path in GaN devices. Hasegawa et al. [13] 
reported that tunneling played an important role in the current transport across the $n$-type GaN Schottky contacts even for low doping densities $\left(1 \times 10^{17} \mathrm{~cm}^{-3}\right)$. The effects of the threading dislocation density on the Ni/n-type GaN Schottky diode have been pointed out using the forward current-voltage-temperature measurements by Yu et al. [14] and Arehart et al. [15]. Yu et al. [14] observed a difference between the calculated and measured Richardson constant value. They attributed the discrepancy to the enhanced tunneling current component. In our previously published study $[16,17]$, we demonstrated that the current transport under forward bias in a wide temperature range across the $\mathrm{Ni} /$ AlInN interface was the tunneling current. Similar results were reported by Donaval et al. [18] at the Ni/InAlN/GaN Schottky diodes. The unrealistically large ideality factors obtained from the $I-V$ characteristics in a wide forward bias voltage range in InGaN/GaN Multiple Quantum Well LEDs [4], InGaN/AlGaN/GaN double-heterostructure blue LEDs [19], InGaN LEDs [20] were explained by tunneling current mechanisms.

On the other hand, there are only limited works that have been done on the current-transport mechanisms in the Schottky contacts of metal $/ p$-InGaN and metal $/ n$-InGaN. For example, Jang et al. [21] investigated the electrical characteristics of Pt $/ n$-InGaN Schottky diodes, and they found a large difference in the SBHs obtained by the TE and TFE modes using the $I-V$ data. And they demonstrated that the SBHs obtained by the TFE mode were fairly similar to those attained by the capacitance-voltage measurements. They attributed the different SBH behaviors that were obtained using the TE and TFE modes to the presence of the different types of native point defects. Chen et al. [22] reported that the thermionic emission is a dominating current transport mechanism at the $\mathrm{Pt} / n$-InGaN interface in a low background carrier concentration $\left(7.7 \times 10^{18} \mathrm{~cm}^{-3}\right)$ sample, but the defect-assisted tunneling current and trap-related recombination current play important roles in high background carrier concentration $\left(5.0 \times 10^{17}\right.$ and $1.2 \times 10^{18} \mathrm{~cm}^{-3}$ ) samples.

However, to our knowledge, there is no reported study on the current mechanisms of metal/p-InGaN Schottky contacts in the literature. Because of only limited works on the electrical characteristics of Schottky barriers in metal-InGaN Schottky contacts, in this work we investigated the current-conduction mechanisms of Pt metal Schottky contacts on $p$-InGaN and $n$-InGaN layers by means of $I-V-T$ measurements data, and analysis was done by using thermionic emission (TE) and tunneling (TU) transport models in a temperature range of $80-360 \mathrm{~K}$.

\section{Experimental procedure}

Epitaxial Mg doped $p$-type $\operatorname{In}_{x} \mathrm{Ga}_{1-x} \mathrm{~N}(x \approx 0.24)$ and $n$-type $\operatorname{In}_{x-}$ $\mathrm{Ga}_{1-x} \mathrm{~N}(x \approx 0.22)$ layers ( $190 \mathrm{~nm}$ thick) were grown on doublepolished 2-in. diameter sapphire $\left(\mathrm{Al}_{2} \mathrm{O}_{3}\right)$ substrates in a low pressure MOCVD reactor (Aixtron 200/4 HT-S) by using trimethylgallium (TMGa), trimethylaluminum (TMAl), and ammonia as $\mathrm{Ga}, \mathrm{Al}$, and $\mathrm{N}$ precursors, respectively. Prior to epitaxial growth, $\mathrm{Al}_{2} \mathrm{O}_{3}$ substrate was annealed at $1120^{\circ} \mathrm{C}$ for $15 \mathrm{~min}$ in order to remove surface contamination. The buffer structures of the Mg-doped $p$-InGaN samples consisted of a $10 \mathrm{~nm}$ thick, low-temperature $\left(770^{\circ} \mathrm{C}\right)$ AlN nucleation layer, and high temperature $\left(1150^{\circ} \mathrm{C}\right) 320 \mathrm{~nm}$ AlN templates. A $2 \mu \mathrm{m}$ nominally undoped GaN layer was grown on an AlN template layer at $1080^{\circ} \mathrm{C}$, followed by a $190 \mathrm{~nm}$ thick $p$-InGaN layer grown at $745^{\circ} \mathrm{C}$. The InGaN layer was doped with $\mathrm{Mg}$ by using a bis-cyclopentadienyl magnesium $\left(\mathrm{Cp}_{2} \mathrm{Mg}\right)$ source. In the $n$-type InGaN sample, $10 \mathrm{~nm}$ low-temperature $\left(575^{\circ} \mathrm{C}\right) \mathrm{GaN}$ and $2.6 \mu \mathrm{m} \mathrm{GaN}$ (grown at $1100^{\circ} \mathrm{C}$ ) buffer layer used. Finally, a $190 \mathrm{~nm}$ thick $n$-InGaN layer was grown at $745^{\circ} \mathrm{C}$. The Hall mobility and carrier density of the $p$-InGaN and $n$-InGaN samples were determined by a Hall measurement to be 1.7 and $203 \mathrm{~cm}^{2} / \mathrm{V} \mathrm{s}$ and $7.5 \times 10^{18}$ and $1.2 \times 10^{18} \mathrm{~cm}^{-3}$, respectively.

Prior to ohmic contact formation, the samples were cleaned with acetone in an ultrasonic bath. After acetone cleaning, the samples were treated with boiling isopropyl alcohol for $5 \mathrm{~min}$ and rinsed in de-ionized (DI) water having $18 \mathrm{M} \Omega$ resistivity. Then, the samples were dipped in a solution of $\mathrm{HCl} / \mathrm{H}_{2} \mathrm{O}(1: 2)$ for $30 \mathrm{~s}$ in order to remove the surface oxides, and rinsed in DI water again for a prolonged period. After cleaning, the ohmic contacts were formed as a square van der Pauw shape and the Schottky contacts formed as $1 \mathrm{~mm}$ diameter circular dots by using electron beam evaporation at approximately $10^{-7}$ Torr vacuum values. The $\mathrm{Ti} / \mathrm{Al} / \mathrm{Ni} / \mathrm{Au}$ $(20 / 170 / 50 / 90 \mathrm{~nm})$ metals were thermally evaporated on the sample and were annealed at $650{ }^{\circ} \mathrm{C}$ for $30 \mathrm{~s}$ in $\mathrm{N}_{2}$ ambient in order to form the ohmic contact. Schottky contacts were formed by $\mathrm{Ni} / \mathrm{Au}(60 / 90 \mathrm{~nm})$ evaporation.

The Ga, Indium (In) compositions and the crystalline quality of the $\operatorname{In}_{x} \mathrm{Ga}_{1-x} \mathrm{~N}$ layers were examined by using a Rigaku SmartLab high-resolution diffractometer system (HR-XRD), delivering a $\mathrm{CuK}_{\alpha 1}(1.54 \AA)$ radiation, using a prodded mirror, 4-bounce Ge (220) symmetric monochromator.

The temperature dependence of the current-voltage $(I-V)$ measurements of the Pt $/ p$-InGaN and Pt $/ n$-InGaN Schottky contacts were done in the range of $80-360 \mathrm{~K}$ by using a temperature controlled MMR VTHS cryostat. The sample temperature was continually monitored by using a copper-constant thermocouple close to the sample and the $I-V$ measurements were performed with a Keithley model 6517A Electrometer/High Resistance Meter.

\section{Results and discussions}

The alloy compositions of the $p-\operatorname{In}_{x} \mathrm{Ga}_{1-x} \mathrm{~N}$ and $n-\operatorname{In}_{x} \mathrm{Ga}_{1-x} \mathrm{~N}$ layers were determined by HR-XRD measurements [23,24]. The lattice mismatch between $\mathrm{GaN}$ and $\mathrm{In}_{x} \mathrm{Ga}_{1-x} \mathrm{~N}$ can be as high as about $10 \%$, depending on the indium (In) molar fraction $(x)$, therefore the growth of InGaN on GaN will lead to strain in the InGaN layer. When the thickness of the InGaN epilayer is smaller than the critical thickness, the InGaN will be pseudomorphically strained $[23,24]$. On the other hand, when the critical thickness is exceeded, strain relaxation occurs through the introduction of extended defects [24].

To evaluate indium composition in InGaN epilayer from XRD measurements two extreme assumptions are usually considered for the state of strain: In the first assumption, the InGaN epilayer is larger than the critical thickness; the layer may be fully relaxed. In the absence of strain in the InGaN epilayer, the actual lattice constant of the relaxed InGaN epilayer corresponds to the measured value. The variation of indium composition is usually assumed to be linear, as in Vegard's law [24]. In the second assumption, the InGaN epilayer is smaller than the critical thickness; the layer may be pseudomorphic. In this case the distortion of the unit cell must be considered. In order to separate the influence of strain and composition, both parameters of the wurtzite lattice, $\mathrm{c}(\mathrm{InGaN})$ and $\mathrm{a}(\mathrm{InGaN})$, have to be measured and compared to their relaxed values [24]. It is often assumed that for $\operatorname{In}_{x} \mathrm{Ga}_{1-x} \mathrm{~N}$ layers of thickness less than about $75 \mathrm{~nm}$, the $\operatorname{In}_{x} \mathrm{Ga}_{1-x} \mathrm{~N}$ grow pseudomorphic to the GaN buffer [24].

Fig. 1 shows $\omega-2 \theta$ scan XRD patterns around the (002) reflection of the $p$-InGaN and $n$-InGaN samples. Three diffraction peaks were observed from the $\operatorname{In}_{x} \mathrm{Ga}_{1-x} \mathrm{~N}$ and GaN and AlN layers in p-type InGaN samples and in $n$-type $\operatorname{In}_{x} \mathrm{Ga}_{1-x} \mathrm{~N}$ sample two diffraction peaks observed from $\operatorname{In}_{x} \mathrm{Ga}_{1-x} \mathrm{~N}$ and GaN layers. The wellresolved diffraction peaks related to $p-\operatorname{In}_{x} \mathrm{Ga}_{1-x} \mathrm{~N}$ and $n-\operatorname{In}_{x} \mathrm{Ga}_{1-x} \mathrm{~N}$ layers were observed at around $33.79^{\circ}$ and $33.86^{\circ}$, respectively. The indium (In) molar fraction $(x)$ were determined from the peak 


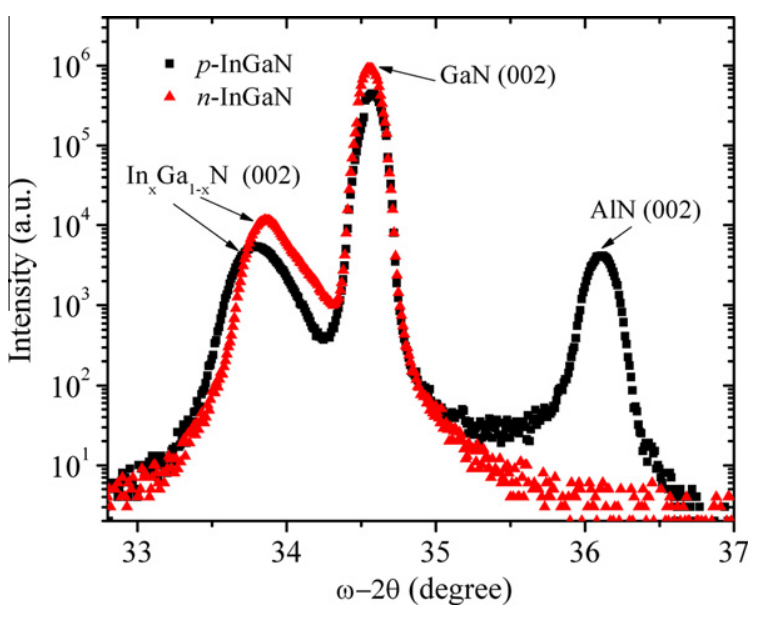

Fig. 1. HR-XRD (002) $\omega-2 \theta$ scans of $p-\operatorname{In}_{x} \mathrm{Ga}_{1-x} \mathrm{~N}$ and $n-\operatorname{In}_{x} \mathrm{Ga}_{1-x} \mathrm{~N}$ samples. The molar fraction of Indium (x) of $\operatorname{In}_{x} \mathrm{Ga}_{1-x} \mathrm{~N}$ alloy in $p$-type $\operatorname{In}_{x} \mathrm{Ga}_{1-x} \mathrm{~N}$ and in $n$-type $\mathrm{In}_{x} \mathrm{Ga}_{1-x} \mathrm{~N}$ samples were $x \sim 0.24$ and 0.22 , respectively.

angles by using Vegard's law with the assumption that the layers are fully relaxed as they are thick enough $(190 \mathrm{~nm})$. The Indium molar fraction $x$ of $\operatorname{In}_{x} \mathrm{Ga}_{1-x} \mathrm{~N}$ alloy in $p$-type $\operatorname{In}_{x} \mathrm{Ga}_{1-x} \mathrm{~N}$ and in $n$ type $\operatorname{In}_{x} \mathrm{Ga}_{1-x} \mathrm{~N}$ samples were $x \sim 0.24$ and 0.22 , respectively.

The current-voltage $(I-V)$ characteristics of the samples investigated were measured at various ambient temperatures ranging between 80 and $360 \mathrm{~K}$. The measurements were taken at the temperatures $80,110,140,170,200,230,260,290,300,320$, 340 , and $360 \mathrm{~K}$. The typical semi-logarithmic forward current density-voltage $(J-V)$ characteristics of the Pt $/ p$-InGaN and Pt $/ n$-InGaN Schottky contacts for selected temperatures are shown in Fig. 2(a) and (b). For clarity, only six curves are plotted in Fig. 2(a) and (b). In the forward bias, a minor increase of $J$ with $T$ is observed for both samples. The logarithmic plots of $J$ against $V$ curves, measured between 80 and $360 \mathrm{~K}$, are straight lines at small forward current where the effect of series resistance is small and can be neglected. At the high forward voltage region, the graphs deviate from the straight lines, which are caused by the voltage drop across the series resistance $[10,16,17]$. Furthermore, all $\ln J-V$ curves appeared to be parallel.

The current density through a Schottky contact at a forward bias $V$, based on the thermionic emission theory is given by $[10,16,17]$,

$J_{T E}=J_{T E}(0)\left(\exp \left[\frac{q\left(V-I R_{S}\right)}{n k T}\right]-1\right)$

where $J_{\mathrm{TE}}(0)$ is the saturation current density and gives,

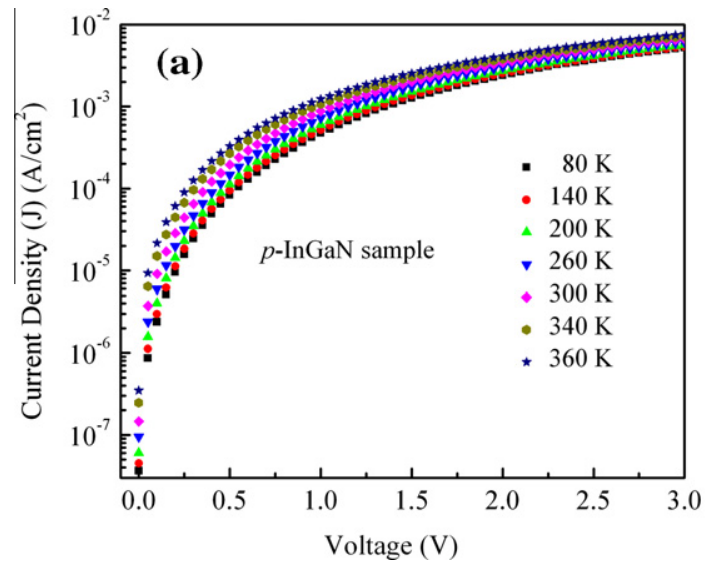

$J_{T E}(0)=A^{*} T^{2} \exp \left[\frac{-q \Phi_{b 0}}{k T}\right]$

In the Eq. (1), $n$ is the ideality factor, $V$ is the applied voltage, $T$ is the absolute temperature, $q$ is the electron charge, $k$ is the Boltzmann constant and $R_{\mathrm{S}}$ is the series resistance. In Eq. (2), $q \Phi_{b 0}$ is the Schottky barrier height (SBH), and $A^{*}\left(A \mathrm{Acm}^{-2} K^{-2}\right)=120 m_{e}^{*} / m_{e}$ is the effective Richardson constant with $m_{e}^{*}$ and $m_{\mathrm{e}}$ being the effective mass of the electron and the rest mass of the electron, respectively. By using an effective mass of $0.183 m_{\mathrm{e}}$ for the electron in $\mathrm{In}_{0.22} \mathrm{Ga}_{0.78} \mathrm{~N}$ and $0.716 m_{\mathrm{h}}$ for hole in $\mathrm{In}_{0.24} \mathrm{Ga}_{0.76} \mathrm{~N}$ layers [25], the value of $A^{*}$ is calculated to be 21.96 and $85.92 \mathrm{~A} \mathrm{~cm}^{-2} \mathrm{~K}^{-2}$ for $n$ - $\operatorname{In}_{0.22} \mathrm{Ga}_{0.78} \mathrm{~N}$ and $p$ - $\operatorname{In}_{0.24} \mathrm{Ga}_{0.76} \mathrm{~N}$ and the samples, respectively. The saturation current $J_{\mathrm{TE}}(0)$ is obtained using the intercept on the current axis of the natural logarithm of the current and is plotted against the applied voltage and Schottky barrier heights $\left(\Phi_{b 0}\right)$ calculated through the relation, as commonly used,

$\Phi_{b 0}=\frac{k T}{q} \ln \left[\frac{A^{*} T^{2}}{J_{0}}\right]$

The slope of the first linear region of forward bias $\ln (J)$ versus $V$ characteristics through the relation gives the value of the ideality factor,

$n=\frac{q}{k T}\left(\frac{d V}{d(\ln I)}\right)$

The values of Schottky barrier heights and the ideality factor of the Pt $/ p$-InGaN and Pt $/ n$-InGaN Schottky contacts at different temperatures are calculated by using Eqs. (3) and (4). The changes in $n$ with temperature are shown in Fig. 3(a) for sample Pt $/ p$-InGaN and the Pt/n-InGaN Schottky contacts. The $n$ values for Pt/p-InGaN Schottky contacts was found to increase with decreasing temperature $(n=8.1$ at $80 \mathrm{~K}, n=2.2$ at $360 \mathrm{~K})$. On the other hand, the ideality factor values for the Pt/n-InGaN Schottky contacts were found to be $n=12.8$ at $80 \mathrm{~K}$ and $n=3.1$ at $360 \mathrm{~K}$. The SBHs values versus temperature are shown in Fig. 3(b) for both Schottky contacts. The calculation results showed that the SBHs values of the $\mathrm{Pt} / p$-InGaN and Pt/n-InGaN are $0.19 \mathrm{eV}$ and 0.13 at $80 \mathrm{~K}$ and $0.89 \mathrm{eV}$ and 0.66 at $360 \mathrm{~K}$, respectively. As seen in Fig. 3(b), both of the $n$ values and SBHs were found to be a strong function of temperature and the $\Phi_{b 0}$ shows the unusual behavior of increasing linearly with an increase in temperature from 80 to $360 \mathrm{~K}$ for both Schottky contacts. Similar temperature dependent behaviors were reported in an early study, not only for GaN [14,15,26], AlGaN [27], AlGaN/GaN [17] and AlInN/GaN [16,18] MS contacts but also for $n$ InGaN $[21,22]$ Schottky contacts. The ideality factor $n$ is a measure of conformity of the diode to thermionic emission and requires the

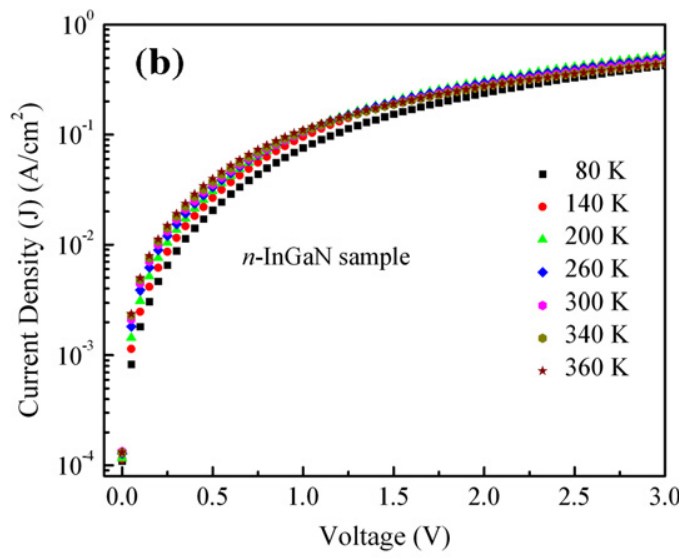

Fig. 2. Measured forward bias current density-voltage $(J-V)$ characteristics of (a) for the Pt/p-InGaN and (b) Pt/n-InGaN Schottky contacts at different temperatures. 

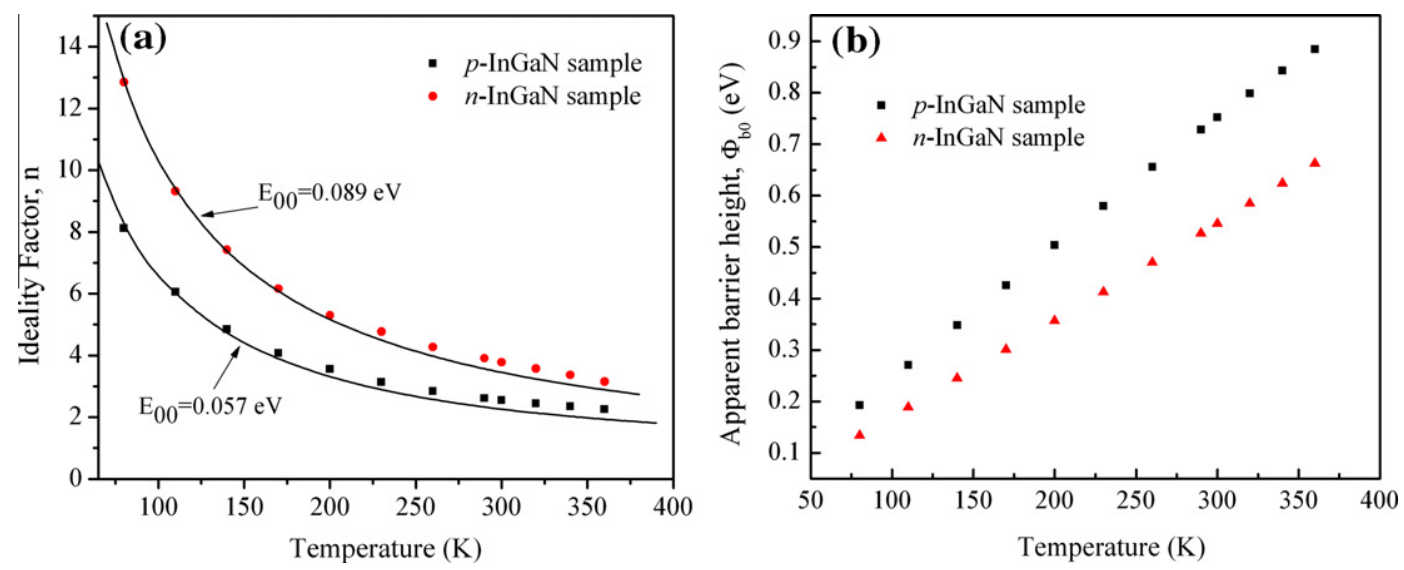

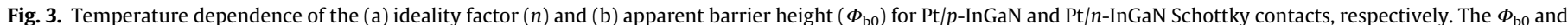
$n$ values by using Eqs. (3) and (4), respectively.

$n$ to be constant for different temperatures and close to 1 [10]. However, the strong increase in the barrier height with increased temperature cannot be explained theoretically, which indicates that the main current mechanism in the both Schottky contacts is associated with carrier tunneling current rather than thermionic emission current [14-18,26].

The analytical expressions for the forward biased current-voltage $J-V$ relationship can be given by the following equations based on the tunneling model $[10,15,16]$,

$J_{T U}=J_{T U}(0)\left(\exp \left[\frac{q\left(V-I R_{S}\right)}{E_{0}}\right]-1\right)$

$J_{T U}(0)$ is the tunneling saturation current and $E_{0}$ is the tunneling parameter. $E_{0}$ can be defined as $[10,15,16]$,

$n k T=E_{0}=E_{00} \operatorname{coth}\left(q E_{00} / k T\right)$

$E_{00}=\frac{q h}{4 \pi} \sqrt{\frac{N_{d}}{\varepsilon_{0} \varepsilon_{s} m^{*}}}$

In Eq. (6), $E_{00}$ is the characteristic tunneling energy that is related to the tunnel effect transmission probability and determines the relative importance of tunneling and TFE. In Eq. (7), $q$ is the electron charge, $h$ is the Planck constant, $N_{\mathrm{d}}$ is the carrier concentration, $\varepsilon_{0} \varepsilon_{s}$ is the dielectric constant of the semiconductor and $m^{*}$ is the effective mass of the semiconductor. The accurate values of $J_{T U}(0)$ and $E_{0}$ are determined from the intercept on the vertical axis and the slope of the $\ln (J)$ versus the $V$ curve at small forward current.
The tunneling parameter values for Pt/p-InGaN Schottky contacts were found to change between 56 and $69 \mathrm{meV}$ and in Pt/n-InGaN Schottky contacts, the $E_{0}$ values change between 89 and $98 \mathrm{meV}$. Fig. 4(a) and (b) shows a plot of $J_{\mathrm{TU}}(0)$ and $E_{0}$ versus temperature from 80 to $360 \mathrm{~K}$, for Pt/p-InGaN and Pt $/ n$-InGaN Schottky contacts. By plotting the ideality factor versus temperature and comparing with Eq. (6), $E_{00}$ can be estimated, which was approximately 57 and $89 \mathrm{meV}$ for the Pt/p-InGaN and Pt/n-InGaN, respectively. The characteristic tunneling energy $\left(E_{00}\right)$ for Pt/p-InGaN and $\mathrm{Pt} / n$-InGaN Schottky contacts results from the fitting procedure, which corresponds to the $p$-InGaN and $n$-InGaN layer doping of $6.3 \times 10^{19} \mathrm{~cm}^{-3}$ and $3.8 \times 10^{19} \mathrm{~cm}^{-3}$, respectively. This is approximately one order bigger than the residual doping of $p$-InGaN, and the $n$-InGaN samples used in our experiments as determined by a Hall measurement, were expected to be around $7.5 \times 10^{18}$ and $2 \times 10^{18} \mathrm{~cm}^{-3}$.

The temperature dependence of the ideality factor can be explained as a cross over from TE to tunneling or TFE through the barrier $[10,14,16]$. The relative contributions of the FE, TFE and TE transport components depend on both the doping level and temperature. According to the theory, a rough criterion can be given by comparing the thermal energy $k T$ to $E_{00}$. When $k T \ll E_{00}$, FE (or tunneling) dominates. When the $k T \gg E_{00}$, TE dominates and the original Schottky-barrier behavior prevails without tunneling and When $k T=E_{00}$, TFE is the main mechanism in Schottky contacts [10].

However, the theoretical value of $E_{00}$ parameters in our study for $\mathrm{Pt} / p$-InGaN and $\mathrm{Pt} / n$-InGaN samples (with $6.3 \times 10^{19}$ and $3.8 \times 10^{19} \mathrm{~cm}^{-3}$ doping levels, respectively) are 9.1 and $18 \mathrm{meV}$,
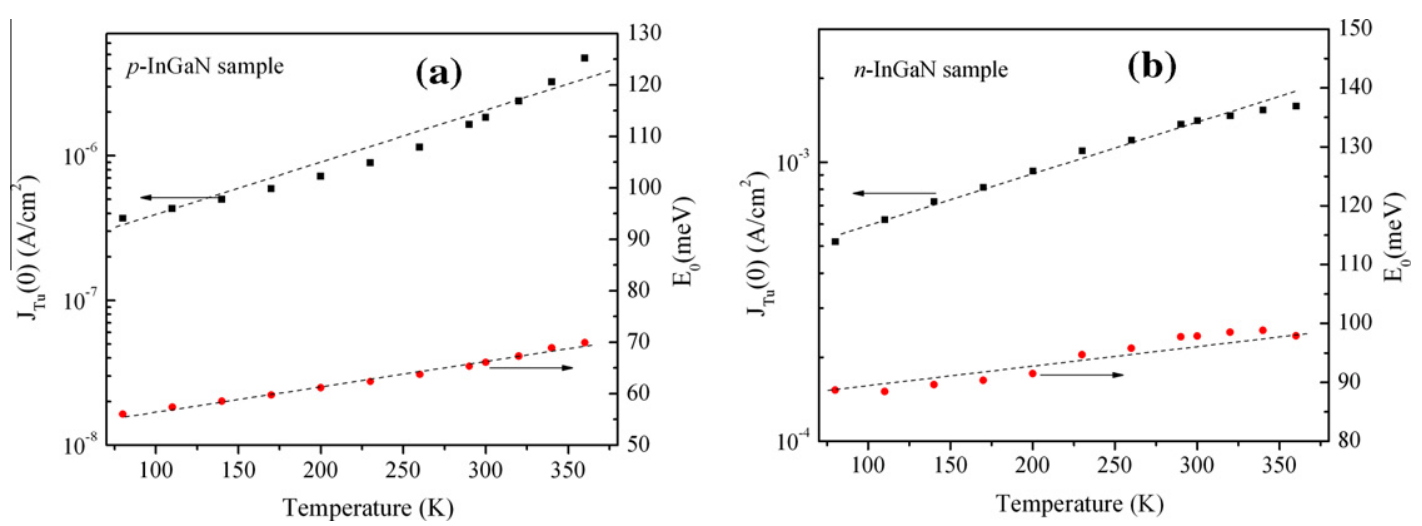

Fig. 4. Temperature dependence of tunneling saturation current density $J_{\mathrm{TU}}(0)$ and tunneling parameter $E_{0}$ for (a) Pt/p-InGaN and (b) Pt/n-InGaN Schottky contacts. 
respectively, and are quite small and the contribution from tunneling is negligible. It is well known that GaN usually has a high dislocation density, much more than those in Si and GaAs [6,7]. If there were many defects near the surface region, electrons could go through the barrier by defect-assisted tunneling, thus greatly increasing the tunneling probability [14-20].

In the recent published study, the effects of intentionally introduced defects on the electronic properties of $n$ - $\operatorname{In}_{x} \mathrm{Ga}_{1-x} \mathrm{~N}$ were investigated. Pantha et al. [28] demonstrated the origin of the background electron concentration in $\operatorname{In}_{x} \mathrm{Ga}_{1-x} \mathrm{~N}$. They reported that the background electron concentration increases sharply with an increase in $x$ for $x<0.5$ and became almost constant $\left(n \sim 1 \times 10^{19}\right.$ $\mathrm{cm}^{-3}$ ) for $x>0.5$. In their study, they suggest that the formation of nitrogen vacancy $\left(V_{N}\right)$ related impurities due to an insufficient supply of $\mathrm{N}$ atoms at reduced growth temperatures $\left(600^{\circ} \mathrm{C}\right)$ is primarily responsible for the high background electron concentration and this $\mathrm{V}_{\mathrm{N}}$-related donor is very shallow in In-rich InGaN alloys. Its energy level decreases with an increase in In content and cross over the conduction band at $x \sim 0.5$. In addition, Li et al. [29] also demonstrated that the InGaN has a large amount of native donor defects, which are the most likely source of surface electrons, and that the defect concentration is sensitively dependent on the $\mathrm{Ga} / \mathrm{In}$ ratio.

Jang et al. [21] published a study on the current transport mechanisms on Pt/n-InGaN Schottky barrier. In their study, they showed that there is a large difference in the SBHs obtained by the TE and TFE modes using the $I-V$ data. They have been attributed to the presence of different types of native point defects in the InGaN layer. In a study by Chen et al. [22], they demonstrated that the thermionic emissions are a dominating current transport mechanism at the $\mathrm{Pt} / n$-InGaN interface in a low background carrier concentration $\left(7.7 \times 10^{16} \mathrm{~cm}^{-3}\right)$ sample, while the defect-assisted tunneling current and trap-related recombination current play important roles in high background carrier concentration $\left(5.0 \times 10^{17}\right.$ and $\left.1.2 \times 10^{18} \mathrm{~cm}^{-3}\right)$ samples.

As can be seen in Fig. 4(a) and (b), we observed a weak temperature dependence of the saturation current $\left(J_{\mathrm{TU}}(0)\right)$ and a fairly small dependence on the temperature of the tunneling parameters $\left(E_{0}\right)$ in the temperature range of $80-360 \mathrm{~K}$ for both samples. While thermionic emission always gives strong temperature dependence, thermionic field emission can be much less temperature dependent [10-12,16-18]. That is the case because it has been commonly accepted that a temperature insensitive tunneling parameter and weak temperature dependence in saturation current are typical features of a defect-assisted tunneling current in the InGaN layer with high dislocation density [21,22]. It has been already reported that the current transport in metal/GaN
Schottky diodes can be described by a multistep tunneling along dislocations [11,12,16-18].

The current mechanisms in the III-V heterojunctions have shown that they are generally governed by multistep tunneling with the involvement of dislocations even at room temperature and a model of tunneling through a space charge region (SCR) along a dislocation line (tube) is suggested [11,12,16-18]. The dislocations with a screw component and V-defects have been suggested to be the primary tunneling path in GaN devices [11,12]. Moreover, many studies have demonstrated that an excess tunnel current can be attributed to dislocations [11,12,14-18].

The deviation from the linearity in the forward bias $I-V$ characteristics is due to the effect of the series resistance $\left(R_{\mathrm{S}}\right)$ of the structure when the applied bias voltage is sufficiently large. The $R_{\mathrm{S}}$ is significant in the downward curvature at the high bias voltages of the forward-bias $I-V$ characteristics. The series resistance and the other main electrical parameters, such as the ideality factor $(n)$, the barrier height $\left(q \Phi_{b 0}\right)$ can be evaluated in the high voltage region where the $I-V$ characteristics are not linear using a method developed by Cheung and Cheung [30]. The Cheung's function, from the forward bias $I-V$ characteristics due to the thermionic emission of the Schottky contact with series resistance, can be defined as [30,31],

$\frac{d V}{d \ln I}=I R_{S}+\left(\frac{n k T}{q}\right)$

The Eq. (6) should give a straight line for the data of the downward-curvature region in the forward-bias $I-V$ characteristic. The experimental plot of $\mathrm{d} V / \mathrm{d}(\ln I)$ versus $I$ at different temperatures for the Pt/p-InGaN and Pt/n-InGaN Schottky contacts are shown in Fig. 5(a) and (b), respectively. Eq. (7) should give a straight line for the data of the downward region in the forward bias $I-V$ characteristics. The slope of the plot of $\mathrm{d} V / \mathrm{d}(\ln I)$ versus $I$ plot gives $R_{\mathrm{s}}$. The values of $R_{\mathrm{s}}$, for Pt $/ p$-InGaN and Pt $/ n$-InGaN Schottky contacts, versus temperature determined from Cheng functions are shown in Fig. 6. As shown in Fig. 6, the $R_{\mathrm{s}}$ values obtained from the Cheung function for the Pt/p-InGaN Schottky contact, the series resistance of the device strongly increases with decreasing temperature. Increase in the $R_{\mathrm{s}}$ value at a low temperature can be explained as a lack of free charge at low temperature [31,32]. Similar temperature dependence was published as a result of the simulation and experimental measurements of the forward $I-V$ curves [31,32]. However, the $R_{\mathrm{s}}$ values calculated for the Pt $/ n$-InGaN Schottky contact shows the usual behavior expected for semiconductors
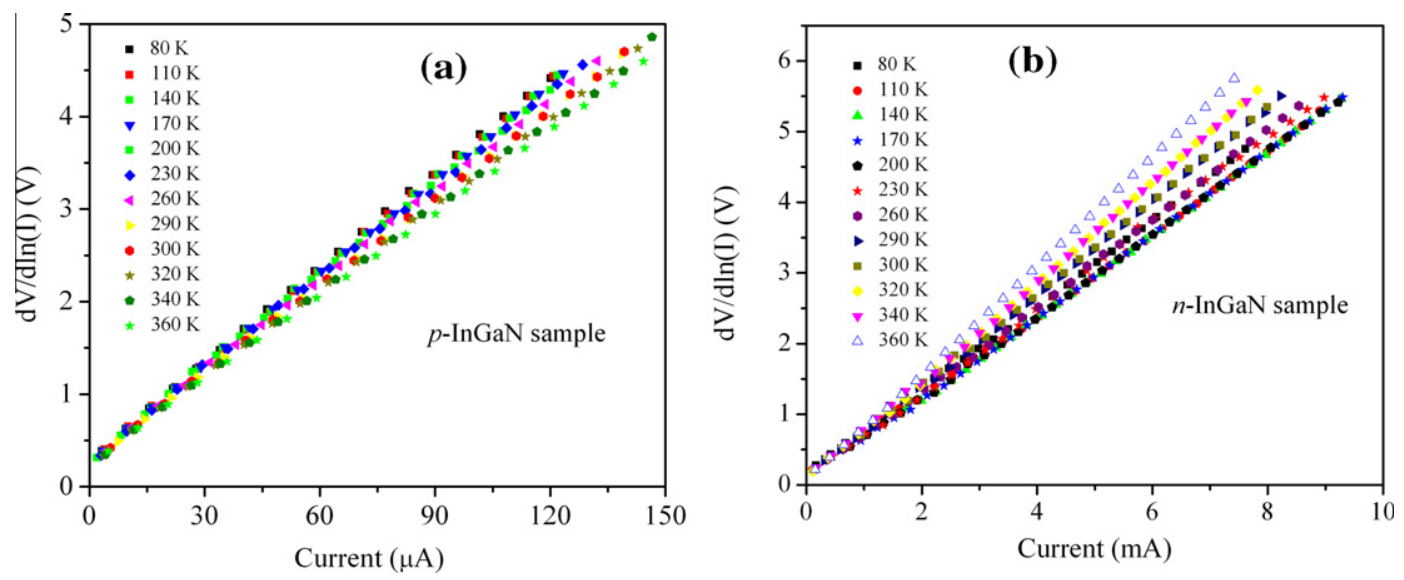

Fig. 5. Experimental $\mathrm{dV} / \mathrm{d}(\mathrm{ln} \mathrm{I}$ ) versus I curves for the (a) Pt/p-InGaN and (b) Pt/n-InGaN Schottky contacts at different temperatures (80-360 K). 


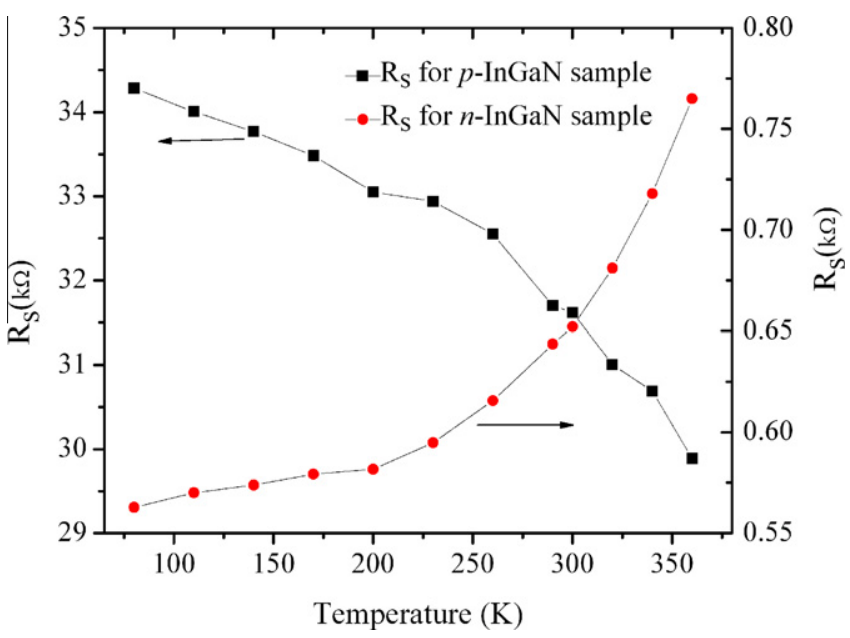

Fig. 6. Temperature dependence of the series resistance for (a) Pt/p-InGaN and (b) $\mathrm{Pt} / n$-InGaN Schottky contacts as determined by Cheung and Cheung's method.

wherein it increases with an increase in temperature. Such behavior can be explained as the no freeze-out of carriers in the low temperature region $[10,33]$.

\section{Conclusion}

In the present work, we studied the current-transport mechanism in the Pt $/ p$-InGaN and Pt/n-InGaN Schottky contacts in forward-bias voltage and a wide range of temperatures (80-360 K). We observed a weak temperature dependence of the saturation current and a fairly small dependence on the temperature of the tunneling parameters in the measured temperature range (80$360 \mathrm{~K})$. The results indicate that the dominant mechanism of the charge transport across the Pt/p-InGaN and Pt/n-InGaN Schottky contacts are electron tunneling to deep levels in the vicinity of mixed/screw dislocations in the temperature range of $80-360 \mathrm{~K}$.

\section{Acknowledgments}

This work is supported by the Projects DPT-HAMIT, ESF-EPIGRAT, EU-N4E, and NATO-SET-181, and TUBITAK under the Project Nos. 107A004, 107A012, and 109E301. One of the authors (E.O.) also acknowledges partial support from the Turkish Academy of Sciences.

\section{References}

[1] S. Nakamura, S. Pearton, G. Faso, The Blue Laser Diode, Springer-Verlag, The complete story, 2000.

[2] H.C. Casey, J. Muth, S. Krishnankutty, J.M. Zavada, Appl. Phys. Lett. 68 (1996) 2867.

[3] Z.L. Li, P.T. Lai, H.W. Choi, IEEE Photonics Technol. Lett. 21 (2009) 1429

[4] X.A. Cao, E.B. Stokes, P.M. Sandvik, S.F. LeBoeuf, J. Kretchmer, D. Walker, IEEE Electron Device Lett. 23 (2002) 535.

[5] F.K. Yam, Z. Hassan, Superlattices Microstruct. 43 (2008) 1

[6] J.S. Speck, S.J. Rosner, Phys. B 273-274 (1999) 24.

[7] X.H. Wu, P. Fini, E.J. Tars, B. Heying, S. Keller, U.K. Mishra, S.P. Den Baars, J.S. Speck, J. Crys. Growth 189 (190) (1998) 231.

[8] S.X. Li, K.M. Yu, J. Wu, R.E. Jones, W. Walukiewicz, J.W. Ager III, W. Shan, E.E. Haller, H. Lu, W.J. Schaff, Phys. Rev. B 71 (2005) 161201.

[9] T.D. Veal, P.H. Jefferson, L.F.J. Piper, C.F. McConvilleb, T.B. Joyce, P.R. Chalker, L. Considine, Appl. Phys. Lett. 89 (2006) 202110.

[10] S.M. Sze, Physics of Semiconductor Devices, second ed., Willey, New York, 1981.

[11] A.E. Belyaev, N.S. Boltovets, V.N. Ivanov, V.P. Kladko, R.V. Konakova, Semiconductors 42 (2008) 689.

[12] V.V. Evstropov, M. Dzhumaeva, Yu.V. Zhilyaev, N. Nazarov, A.A. Sitnikova, L.M. Fedorov, Fiz. Tekh. Poluprovodn. 34 (2000) 1357. Semiconductors 34 (2000) 1305.

[13] H. Hasegawa, S. Oyama, J. Vac. Sci. Technol. B 20 (2002) 1647.

[14] L.S. Yu, Q.Z. Liu, Q.J. Xing, D.J. Qiao, S.S. Lau, J. Redwing, J. Appl. Phys. 84 (1998) 2099.

[15] A.R. Arehart, B. Moran, J.S. Speck, U.K. Mishra, S.P. DenBaars, S.A. Ringel, J. Appl. Phys. 100 (2006) 023709.

[16] E. Arslan, S. Altındal, S. Özcelik, E. Ozbay, Semicond. Sci. Technol. 24 (2009) 075003.

[17] E. Arslan, S. Altindal, S. Ozcelik, E. Ozbay, J. Appl. Phys. 105 (2009) 023705.

[18] D. Donoval, A. Chvala, R. Sramaty, J. Kovac, E. Morvan, Ch. Dua, M.A. DiFortePoisson, P. Kordos, J. Appl. Phys. 109 (2011) 063711.

[19] Piotr Perlin, Marek Osinski, Petr G. Eliseev, Vladimir A. Smagley, Mu Jian, Michael Banas, Philippe Sartori, Appl. Phys. Lett. 69 (1996) 1680.

[20] C.L. Reynolds Jr., J. Appl. Phys. 103 (2008) 086102.

[21] Ja.-Soon. Jang, J. Appl. Phys. 99 (2006) 073704.

[22] D.J. Chen, Y. Huang, B. Liu, Z.L. Xie, R. Zhang, Y.D. Zheng, Y. Wei, V. Narayanamurti, J. Appl. Phys. 105 (2009) 063714.

[23] M. Schuster, P.O. Gervais, B. Jobst, W. Hosler, R. Averbeck, H. Riechert, A. Iberl, R. Stommerk, J. Phys. D: Appl. Phys. 32 (1999) A56.

[24] K.P. O'Donnell, J.F.W. Mosselmans, R.W. Martin, S. Pereira, M.E. White, J. Phys.: Condens. Matter. 13 (2001) 6977.

[25] H. Morkoç, Handbook of Nitride Semiconductors and Devices Vols. I-III, WileyVCH, New York, 2008.

[26] Yow.-Jon. Lin, J. Appl. Phys. 106 (2009) 013702.

[27] C.J. Cheng, J.J. Si, J.X. Ding, X.F. Zhang, L. Zhang, L. Zhao, Z.X. Lu, W.G. Sun, Phys. Status Solidi A 206 (2009) 363.

[28] B.N. Pantha, H. Wang, N. Khan, J.Y. Lin, H.X. Jiang, Phys. Rev. B 84 (2011) 075327.

[29] S.X. Li, K.M. Yu, J. Wu, R.E. Jones, W. Walukiewicz, J.W. Ager III, W. Shan, E.E Haller, Hai Lu, William J. Schaff, Physica B 376-377 (2006) 432.

[30] S.K. Cheung, N.W. Cheung, Appl. Phys. Lett. 49 (1986) 85.

[31] R.K. Gupta, K. Ghosh, P.K. Kahol, Physica E 42 (2010) 1509.

[32] B. Prasanna Lakshmi, M. Siva Pratap Reddy, A. Ashok Kumar, V. Rajagopal Reddy, Curr. Appl. Phys. 12 (2012) 765.

[33] J. Osvald, Z. Horvath, Appl. Surf. Sci. 234 (2004) 349. 